\title{
Evaluation of left atrial function in asymptomatic dogs with chronic myxomatous mitral valve disease: two- dimensional feature-tracking echocardiography and Simpson's monoplanar methods ${ }^{1}$
}

\author{
Mariana R. Coelho ${ }^{2 *}$, Ruthnea A.L. Muzzi², Elaine M.S. Dorneles², \\ Guilherme G. Pereira ${ }^{3}$ D , Rosa M. Cabral², Leonardo A.L. Muzzi², \\ Claudine B. Abreu² and Luiz E.D. Oliveira ${ }^{2}$
}

\begin{abstract}
Coelho M.R., Muzzi R.A.L., Dorneles E.M.S., Pereira G.G., Cabral R.M., Muzzi L.A.L., Abreu C.B. \& Oliveira L.E.D. 2020. Evaluation of left atrial function in asymptomatic dogs with chronic myxomatous mitral valve disease: two-dimensional feature-tracking echocardiography and Simpson's monoplanar methods. Pesquisa Veterinária Brasileira 40(3):188-196. Departamento de Medicina Veterinária, Universidade Federal de Lavras, Av. Doutor Sylvio Menicucci 1001, Cx. Postal 3037, Lavras, MG 37200-000, Brazil. E-mail: marianacoelhorc@gmail.com

The present study evaluated the volume and function of the left atrium by two-dimensional echocardiographic feature-tracking imaging (2D-FTI) and Simpson's monoplanar modeling in dogs with asymptomatic degenerative mitral valve disease (DMVD). The study consisted of 80 dogs that were divided into the following three groups: Group 1, 21 dogs (A); Group 2, 30 dogs (B1) and Group 3, 29 dogs (B2). The variable strain (contraction phase) was significantly lower in Group 3 than in Group 1 (12.92 $\pm 4.54 \times 16.69 \pm 5.74, p=0.014)$, and significant differences in the contraction strain index (CSI) were observed between all of the groups that were evaluated $(1=46.82 \pm 8.10,2=39.88 \pm 8.03,3=35.25 \pm 5.64, \mathrm{p}<0.0001)$. The atrial diastolic volume index (AdVi) that was measured by 2D-FTI was significantly higher in Group 3 than in Group $1(1.31 \pm 0.95 \times 0.96 \pm 0.31, \mathrm{p}=0.038)$, and the atrial cardiac index (ACI) was also higher in Group 3 than in Group $1(102.38 \pm 80.18 \times 78.19 \pm 33.38, \mathrm{p}=0.030)$. Atrial function was assessed by Simpson's monoplanar method, which demonstrated an increase in the left atrial systolic volume, while the contractile function decreased with an increasing disease severity (Group $10.21 \pm 0.06$; Group 2 0.25 \pm 0.06 ; Group 3 0.32 $\pm 0.08, \mathrm{p}<0.0001$ ). The intraobserver and interobserver assessments showed low to moderate variability; most of the values for the coefficient of variation for the variables that were analysed with each method were below 25\%. Thus, DMVD was determined to cause an alteration in atrial function, especially in the contraction phase, and even in asymptomatic animals, and the methods of 2D-FTI echocardiography and Simpson's monoplanar evaluation are sensitive and early methods for the detection of left atrial dysfunction.
\end{abstract}

INDEX TERMS: Evaluation, left atrial, asymptomatic dogs, myxomatous degeneration, mitral valve, echocardiographic, bidimensional tracking, left atrial volume, atrial strain, strain rate.

\footnotetext{
${ }^{1}$ Received on June 25, 2019.

Accepted for publication on August 10, 2019.

2 Departamento de Medicina Veterinária, Universidade Federal de Lavras (UFLA), Av. Doutor Sylvio Menicucci 1001, Cx. Postal 3037, Lavras, MG 37200-000, Brazil. *Corresponding author: marianacoelhorc@gmail.com

3 Naya Cardiologia Veterinária, Rua Conde de Porto Alegre 1761, Campo Belo, São Paulo, SP 04608-003, Brazil.
}

RESUMO.- [Avaliação da função atrial esquerda em cães assintomáticos com degeneração mixomatosa crônica de valva mitral: métodos ecocardiográficos bidimensional feature tracking e monoplanar de Simpson]. 0 presente estudo avaliou o volume e a função atrial esquerda obtidos por meio da ecocardiografia bidimensional feature tracking 
(2D-FTI) e pelo método monoplanar de Simpson em cães saudáveis e cães com DMVD assintomáticos. Foram avaliados 80 cães distribuídos em três grupos: Grupo 1, 21 cães (classe A); Grupo 2, 30 cães (classe B1) e Grupo 3, 29 cães (classe B2). A variável strain (fase de contração) foi significativamente

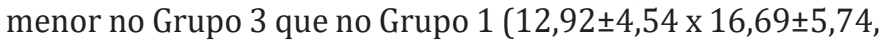
$\mathrm{p}=0,014$ ) e para a variável índice de strain de contração (CSI), houve diferença estatística entre todos os grupos avaliados $(1=46,82 \pm 8,10 ; 2=39,88 \pm 8,03 ; 3=35,25 \pm 5,64, p<0,0001)$. $\mathrm{O}$ índice de volume diastólico atrial (iVdA) mensurado por meio do 2D-FTI foi significativamente maior no Grupo 3 que no Grupo $1(1,31 \pm 0,95 \times 0,96 \pm 0,31, p=0,038)$, assim como para o índice cardíaco atrial (iCA) também foi maior no Grupo $3(102,38 \pm 80,18 \times 78,19 \pm 33,38, p=0,030)$. A função atrial avaliada pelo método monoplanar de Simpson demonstrou um aumento do volume atrial esquerdo e do volume sistólico do átrio esquerdo, enquanto que a função contrátil diminuiu com o aumento da gravidade da doença (Grupo $10,21 \pm 0,06$;

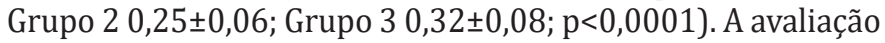
intraobservador e interobservador, demonstrou variabilidade baixa a moderada, uma vez que a maioria dos valores de coeficiente de variação se concentraram abaixo de $25 \%$ para as variáveis analisadas em ambos os métodos. Dessa forma, conclui-se que a DMVD causa alteração na função atrial, principalmente na fase de contração, mesmo em animais assintomáticos e que a ecocardiografia 2D-FTI e o método monoplanar de Simpson são métodos sensíveis e precoces na detecção da disfunção atrial esquerda.

TERMOS DE INDEXAÇ̃̃O: Avaliação, átrio esquerdo, cães assintomáticos, mixomatosa crônica, valva mitral, ecocardiográficos, bidimensional feature tracking, volume atrial esquerdo, Strain e Strain Rate atriais.

\section{INTRODUCTION}

Degenerative mitral valve disease (DMVD) is the most common heart disease in small dogs and causes mitral regurgitation (MR) and myocardial dysfunction. The progression of the disease occurs slowly, and its morbidity is directly related to the magnitude of valve insufficiency, volume overload and severity of atrial remodelling (Borgarelli \& Buchanan 2012).

The left atrium (LA) controls ventricular filling via its three functions: as a reservoir, which occurs during ventricular contraction; as a conduit, which allows the blood to flow passively from the atrium to the left ventricle; and as a booster pump, which is involved in the contraction of the LA (Matsumoto et al. 2014).

The measurement of LA function is essential for cases of DMVD because LA remodelling is a physiological response to volume overload from MR (Fox 2012). However, quantifying LA deformation is challenging because of its complex anatomy, which includes the insertion of pulmonary veins, the presence of the atrial appendage, variable geometry, and small wall thickness (Hoit 2014).

These limitations can be overcome with new echocardiographic tools, including two-dimensional feature-trackingimaging (2D-FTI) echocardiography and the single-plane Simpson's method, which have all been used to assess atrial function. Nonetheless, few veterinary medicine studies to date have evaluated DMVD, demonstrating the need for additional investigation of this subject (Nakamura et al. 2017, Toaldo et al. 2017).
Therefore, the objectives of this study were (1) to determine the feasibility and reproducibility of 2D-FTI echocardiography in assessing LA function in dogs; (2) to compare the measurements of LA function and volume that were obtained from both 2D-FTI echocardiography and the single-plane Simpson's method between healthy dogs and asymptomatic dogs with DMVD; and (3) to correlate the variables that were obtained via 2D-FTI echocardiography to the left atrial to aortic root ratio (LA/Ao) measurements that were obtained by conventional echocardiography.

\section{MATERIALS AND METHODS}

Ethics statement. The data were obtained from the Cardiology Department of the Veterinary Hospital of the "Universidade Federal de Lavras", Lavras/MG, Brazil. The study was approved by the Animal Research Ethics Committee of our institution under Protocol No. 030/17.

Animals. A total of 1,160 echocardiographic examinations that were performed from February 2011 to July 2017 were evaluated, and images that were obtained from 80 dogs (Canis lupus familiaris) were selected for inclusion in the study. The animals were separated into three groups according to the classification proposed by Atkins et al. (2009) as follows: Group 1, class A animals (Control Group, breeds at risk of developing DMVD); Group 2, class B1 animals (presented with DMVD and MR without LA remodelling); Group 3, class B2 animals (presented with DMVD, MR, and cardiac remodelling - LA/Ao >1.5 and/or left ventricular diameter in normalised diastole $>1.7$ - without congestive heart failure). The study animals received a detailed physical examination, electrocardiography, echocardiography, and chest X-rays (when necessary, to exclude pulmonary edema). The inclusion criteria were a presence of systolic murmur in the mitral area, echocardiographic evidence of DMVD, and sufficient image quality to perform analyses using 2D-FTI echocardiography and the single-plane Simpson's method.

Conventional echocardiography. Examinations were performed using echocardiographic equipment (MyLab 40 Esaote $^{\circledR}$, Italy) with 4-10MHz multifrequency ultrasound transducers, an electronic sector scanning system, and simultaneous electrocardiographic recording on the monitor. All examinations were performed without sedation and with the animals gently restrained. The conventional echocardiographic variables that were measured included the LA diameter, aortic (Ao) diameter, and the left atrial/aortic root ratio (LA/ Ao) in the parasternal short-axis view at the level of the great vessels. The conventional echocardiographic examinations were performed as recommended by Thomas et al. (1993). The measurements for the shortening fraction, LV diameter in normalised diastole (LVDd $\mathrm{N}$ ), and LV diameter in normalised systole (LVDs N) were obtained in the M mode as previously described (Cornell et al. 2004). In pulsed Doppler mode, the $\mathrm{E}$ and $\mathrm{A}$ waves of the mitral flow, the E/A ratio, the isovolumic relaxation time (IVRT), the E/IVRT ratio, and the Em, Am and Em/Am variables by tissue Doppler were evaluated.

The atrial volume was measured in the three phases of the LA using a single-plane Simpson's method in the apical four-chamber view. LAEDV, LAESV, LA ejection fraction (LAEF), and LA cardiac output (LACO) were evaluated. The formulas that were used to measure volume in the three phases were as follows: i) reservoir $\left(\mathrm{LAV}_{\text {max }}-\mathrm{LAV}_{\text {min }} / \mathrm{LAV}_{\text {max }}\right)$; ii) conduit $\left(\mathrm{LAV}_{\text {max }}-\mathrm{LAV}_{\text {pre-a }} / \mathrm{LAV}_{\text {max }}\right)$; and iii) contraction $\left(\mathrm{LAV}_{\mathrm{pa}}-\mathrm{LAV}_{\text {min }} / \mathrm{LAV}_{\text {pre-a }}\right)$ as described previously (Blume et al. 2011), where LAV is the left atrial volume and $L A V_{\text {pre-a }}$ is preatrial contraction volume. 
2D-FTI echocardiography. The indices representing atrial deformity and atrial myocardial velocity (strain and strain rate, respectively) were obtained by means of the 2D-FTI method (Fig.1) similar to the one described by Caivano et al. (2016). For this purpose, the two-dimensional images that were acquired in the left parasternal short-axis view and the apical four-chamber view were stored for off-line analysis using Xstrain software version 10.1 and the optical flow algorithm $\left(\right.$ ESAOTE $^{\circledR}$ ). Three consecutive cardiac cycles were analysed using continuous ECG monitoring, with a sampling rate between 50 and 100 frames/s.

The software automatically represented graphically and quantitatively atrial myocardial strain (St) and strain rates (StR) (Fig.2). It was obtained the mean value of the analyzed segments of strain (global St) in the reservoir, conduction and contraction phases, and to obtain the conduction phase the following calculation was used: conduction St = (reservoir St - contraction St). The mean StR of the three phases was automatically measured by the software. The contraction strain index (CSI), which represents the contribution of the active contraction of the LA to the LV filling phase, was calculated using two strain variables (Cameli et al. 2012) as follows: CS = (LAS contraction/LAS reservoir) $\times 100$.
The diastolic volume, systolic volume, and cardiac output values were automatically determined by the 2D-FTI software. These parameters were correlated with body weight (HÖllmer et al. 2013) and were designated as the left atrial end-diastolic volume (LAEDV), left atrial end-systolic volume (LAESV), and cardiac index (CI). The LAEF was measured automatically by the 2D-FTI software.

Statistical analysis. The statistical analysis was performed using GraphPad Prism software version 5.0. The normality of the data distribution was assessed using the Shapiro-Wilk test. The data from different animal classes were analysed using one-way ANOVA and Tukey's post-hoc test. A two-tailed p-value smaller than 0.05 was used to define statistical significance. The intraclass correlation coefficient (ICC) and its 95\% confidence interval were calculated using MedCalc ${ }^{\circledR}$ software version 16.8 to compare the values that were obtained from the two echocardiographic methods. The degree of correlation was defined as follows: ICC $\geq 0.75$ excellent; $0.4 \geq$ ICC $<0.75$ satisfactory to good; and ICC $<0.4$ poor (Fleiss 1981).

The intraobserver variability was obtained from $30 \%$ of the animals, and the interobserver variability was obtained from $60 \%$ of the animals; the animals were randomly assigned to each of these groups. The degree of variability was defined according to the
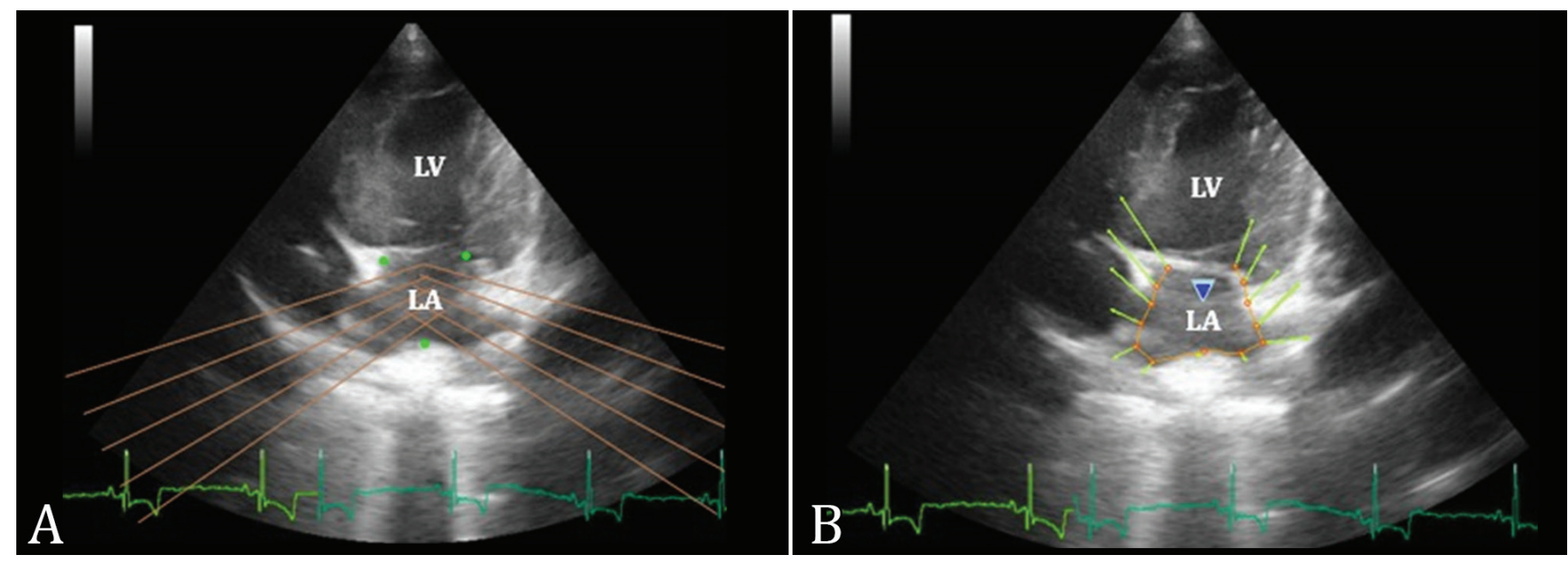

Fig.1. Two-dimensional echocardiographic image showing a semiautomatic tracing of the left atrium (LA) of a healthy dog (A) and velocity vectors (B) using 2D-FTI echocardiography.
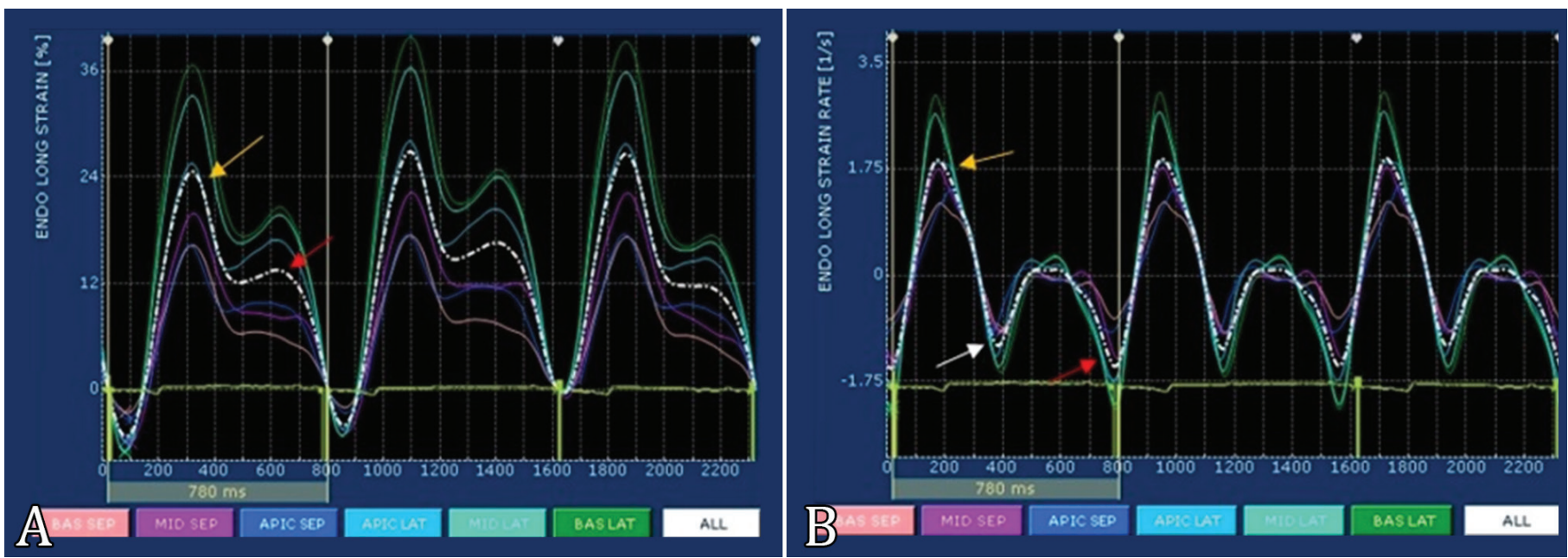

Fig.2. Graphical representation of atrial strain and strain rate in an 8-year-old 10-kg dog of Group 1 (class A). (A) Left atrial strain, (B) left atrial strain rate. Reservoir phase (yellow arrows), contraction phase (red arrows), conduction phase (white arrows). 
coefficient of variation (CV) as follows: $<15 \%$, low; $15-25 \%$, moderate; and $>25 \%$, high (Decloedt et al. 2011). The association between the variables that were derived from 2D-FTI echocardiography (LAEDV, LAESV, CI, CS, LAS, and LASR) and the LA/Ao was tested using a Pearson correlation analysis and was considered significant at $\mathrm{p}<0.05$.

\section{RESULTS}

All of the dogs that were evaluated were of small to medium size and consisted of the following breeds: mixed breed (16), Poodle (14), Pinscher (10), Yorkshire (9), Beagle (8), Teckel
(7), Maltese (4), Schnauzer (4), Shih Tzu (2), Cocker (2), Fox Terrier (1), Pug (1), Lhasa Apso (1) and Pekingese (1).

The data that were obtained from the conventional echocardiography methods and the clinical characteristics of the study sample are presented in Table 1 . The variables for LA function and volume that were obtained by 2D-FTI echocardiography and the single-plane Simpson's method are shown in Table 2 and 3, respectively. For each animal, it was possible to obtain an adequate speckle tracking of the LA, with significant values for LA volume and LAS during contraction. With both the conventional and 2D-FTI echocardiography

Table 1. Clinical characteristics, mean and standard deviation of conventional echocardiography variables of dogs with DMVD at different stages

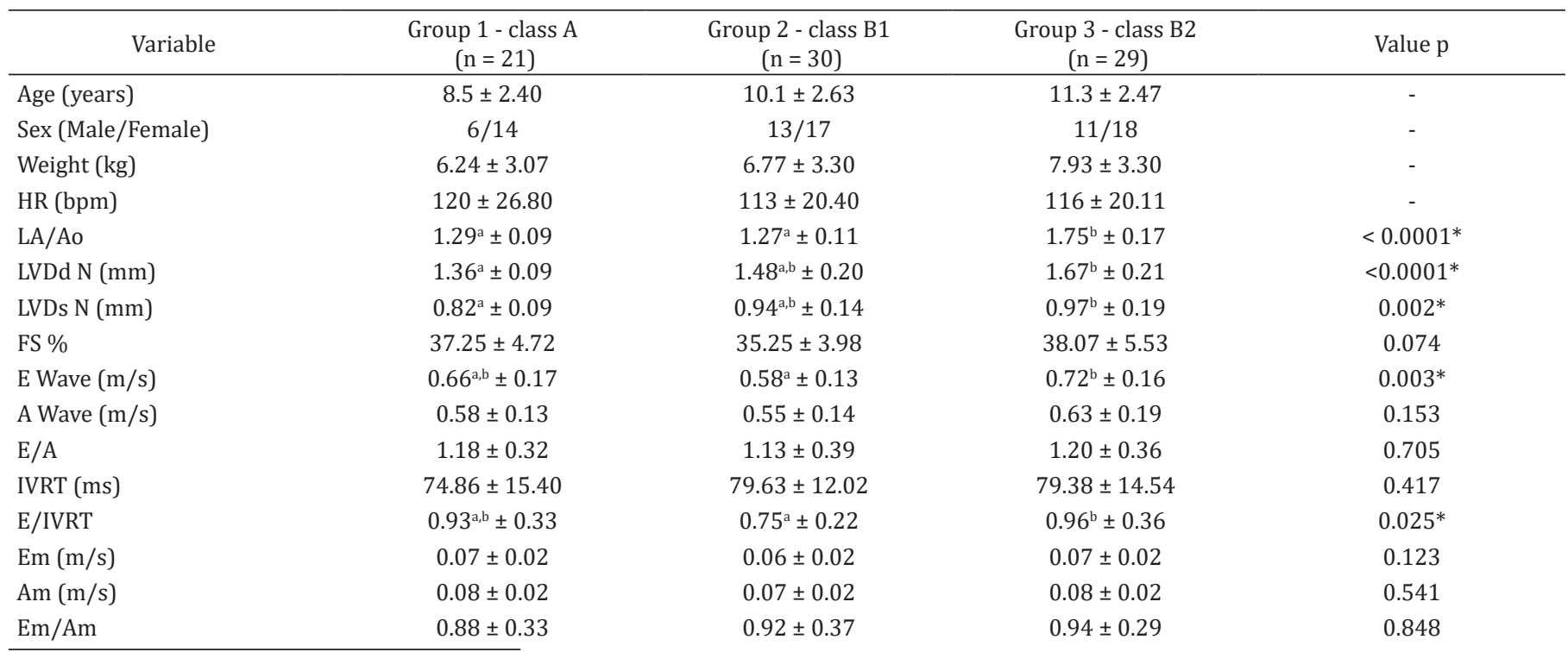

DMVD - degenerative mitral valve disease., $\mathrm{HR}=$ heart rate, LA/Ao = relation between left atrium and aortic root, LVDd $\mathrm{N}=$ left ventricular diameter in diastole normalized by weight, LVDs $\mathrm{N}=$ left ventricular diameter in systole normalized by weight, $\mathrm{FS}=$ fractional shortening, IVRT $=$ isovolumic relaxation time, $\mathrm{E} / \mathrm{IVRT}=$ relation between $\mathrm{E}$ wave and isovolumic relaxation time, $\mathrm{Em}=$ early diastolic velocity of the septal mitral annulus, Am $=$ late diastolic velocity of the septal mitral annulus; ${ }^{a, b}$ different letters on the same line demonstrate statistical significance; * indicates significant difference between groups $(\mathrm{P}<0.05)$.

Table 2. Mean and standard deviation of 2D-FTI echocardiographic variables for left atrial function and volume of dogs with DMVD at different stages

\begin{tabular}{|c|c|c|c|c|}
\hline Variable & $\begin{array}{c}\text { Group } 1 \text { - class A } \\
(\mathrm{n}=21)\end{array}$ & $\begin{array}{c}\text { Group } 2 \text { - class B1 } \\
(\mathrm{n}=30)\end{array}$ & $\begin{array}{c}\text { Group } 3 \text { - class B2 } \\
(\mathrm{n}=29)\end{array}$ & Value $\mathrm{p}$ \\
\hline St reservoir & $36.32 \pm 12.58$ & $36.14 \pm 10.36$ & $37.87 \pm 16.18$ & 0.866 \\
\hline St conduction & $19.64 \pm 7.79$ & $22.16 \pm 9.18$ & $24.95 \pm 12.00$ & 0.081 \\
\hline \multicolumn{5}{|l|}{ Strain Rate (StR) } \\
\hline StR reservoir & $2.66 \pm 0.81$ & $2.62 \pm 0.71$ & $2.77 \pm 0.97$ & 0.763 \\
\hline StR conduction & $1.84 \pm 0.68$ & $2.01 \pm 0.45$ & $2.16 \pm 0.60$ & 0.366 \\
\hline CSI \% & $46.82^{\mathrm{a}} \pm 8.10$ & $39.88^{b} \pm 8.03$ & $35.25^{c} \pm 5.64$ & $<0.0001^{*}$ \\
\hline LAdI (ml/kg) & $0.96^{\mathrm{a}, \mathrm{b}} \pm 0.31$ & $0.89^{\mathrm{a}} \pm 0.42$ & $1.31^{\mathrm{b}} \pm 0.95$ & $0.038^{*}$ \\
\hline LAsI (ml/kg) & $0.31 \pm 0.14$ & $0.28 \pm 0.14$ & $0.42 \pm 0.38$ & 0.108 \\
\hline ACI (mL/min/kg) & $78.19^{\mathrm{a}, \mathrm{b}} \pm 33.38$ & $64.75^{\mathrm{a}} \pm 27.97$ & $102.38^{\mathrm{b}} \pm 80.18$ & $0.030^{*}$ \\
\hline
\end{tabular}

DMVD - degenerative mitral valve disease, $\mathrm{CSI}=$ contraction strain index, LAdI = left atrial diastolic volume index, LAsI = left atrial systolic volume

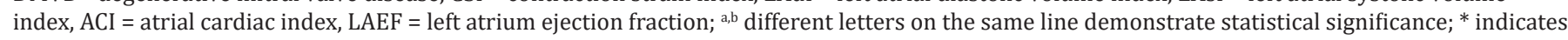
significant difference between groups $(\mathrm{P}<0.05)$. 
methods, the LA volume increased as the disease progressed, especially in Group 3, whereas the LAS during contraction and the CS decreased progressively in the groups of dogs with DMVD. The results using the single-plane Simpson's method indicated that LA volumes in the case of DMVD, regardless of the phase $\left(\mathrm{LAV}_{\max }, \mathrm{LAV} \mathrm{min}_{\text {min }}\right.$, or $\left.\mathrm{LAV} \mathrm{pre- \textrm {a }}_{\mathrm{a}}\right)$, were significantly higher in the animals of the B2 class.

The LA/Ao that was obtained from the conventional echocardiography method was significantly correlated with the LAESV ( $p=0.0082), \operatorname{LAEDV}(p=0.0025), \operatorname{CI}(p=0.0010)$, and CS ( $\mathrm{p}=0025)$ (Fig.3).

The intraobserver and interobserver variabilities were low to moderate because most of the coefficients of variation for the variables that were analysed using both methods were less than $25 \%$. The interobserver variability was high only for LAESV and LAVpre-a (measured using the single-plane Simpson's method) and the LASR conduit (measured by 2D-FTI) (Table 4).

Table 3. Mean and standard deviation of function and volume variables in the atrial phases measured by Simpson's monoplanar method in dogs with DMVD at different stages

\begin{tabular}{|c|c|c|c|c|}
\hline Variable & $\begin{array}{c}\text { Group } 1 \text { - class A } \\
(\mathrm{n}=21)\end{array}$ & $\begin{array}{c}\text { Group } 2 \text { - class B1 } \\
(\mathrm{n}=30)\end{array}$ & $\begin{array}{c}\text { Group } 3 \text { - class B2 } \\
(\mathrm{n}=29)\end{array}$ & Value $\mathrm{p}$ \\
\hline Left atrial ejection fraction (\%) & $65.46 \pm 4.60$ & $66.54 \pm 5.72$ & $68.72 \pm 4.95$ & 0.0767 \\
\hline Cardiac output (ml/kg/min) & $64.25 \pm 16.57^{a}$ & $75.52 \pm 35.47^{\mathrm{a}}$ & $130.29 \pm 74.73^{\mathrm{b}}$ & $<0.0001^{*}$ \\
\hline Maximum volume (ml/kg) & $0.78 \pm 0.22^{\mathrm{a}}$ & $0.92 \pm 0.27^{\mathrm{a}}$ & $1.58 \pm 0.77^{\mathrm{b}}$ & $<0.0001^{*}$ \\
\hline Atrial pre-contraction volume (ml/kg) & $0.36 \pm 0.11^{\mathrm{a}}$ & $0.42 \pm 0.13^{\mathrm{a}}$ & $0.74 \pm 0.44^{\mathrm{b}}$ & $<0.0001^{*}$ \\
\hline Mnimum volume (ml/kg) & $0.28 \pm 0.09^{\mathrm{a}}$ & $0.31 \pm 0.09^{\mathrm{a}}$ & $0.50 \pm 0.29^{\mathrm{b}}$ & $<0.0001^{*}$ \\
\hline Reservoir (ml/kg) & $0.64 \pm 0.04^{\mathrm{a}}$ & $0.66 \pm 0.06^{\mathrm{a}, \mathrm{b}}$ & $0.69 \pm 0.04^{\mathrm{b}}$ & $0.0028^{*}$ \\
\hline Conduction (ml/kg) & $0.54 \pm 0.05$ & $0.54 \pm 0.07$ & $0.53 \pm 0.06$ & 0.9566 \\
\hline Contraction $(\mathrm{ml} / \mathrm{kg})$ & $0.21 \pm 0.06^{\mathrm{a}}$ & $0.25 \pm 0.06^{\mathrm{a}}$ & $0.32 \pm 0.08^{\mathrm{b}}$ & $<0.0001^{*}$ \\
\hline
\end{tabular}

DMVD - degenerative mitral valve disease; ${ }^{\mathrm{a}, \mathrm{b}}$ different letters on the same line demonstrate statistical significance; ${ }^{*}$ indicates significant difference between groups $(\mathrm{P}<0.05)$.
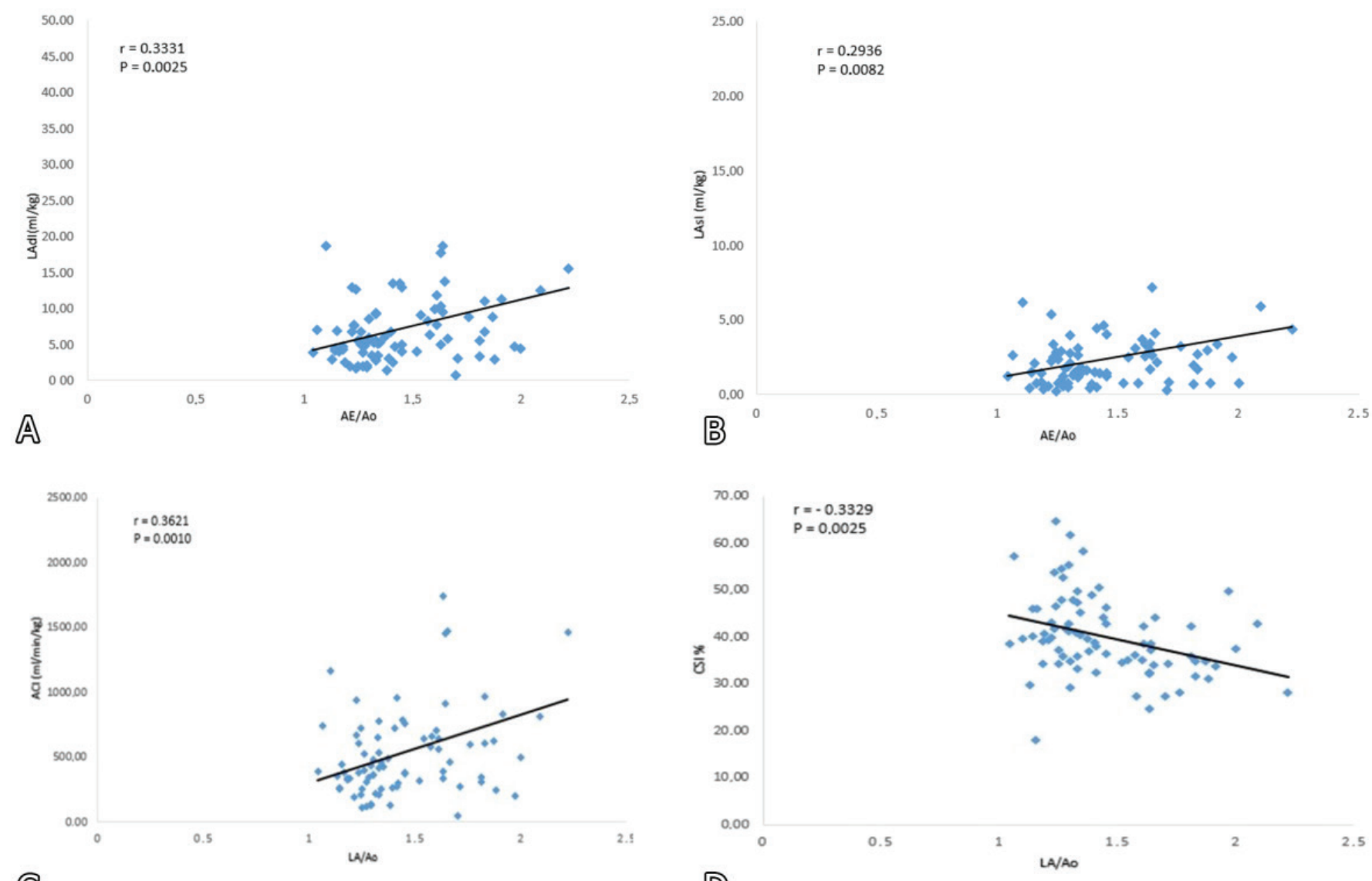

Fig.3. Scatter plots of four variables selected for atrial function correlated with LA/Ao ratio, analyzed by Pearson's correlation ( $\mathrm{p}<0.05$ ). LAsI = atrial systolic volume index, LAdI = atrial diastolic volume index, ACI = atrial cardiac index, CSI = contraction strain index. 
Table 4. Intra and interobserver coefficient of variation (CV) of the echocardiographic variables analyzed by Simpson's monoplanar and 2D-FTI methods in dogs with DMVD at different stages

\begin{tabular}{|c|c|c|}
\hline \multicolumn{3}{|c|}{ Variable } \\
\hline \multicolumn{3}{|l|}{ Vd (ml) } \\
\hline \multicolumn{3}{|l|}{ Vs (ml) } \\
\hline \multicolumn{3}{|l|}{ Vpc (ml) } \\
\hline \multicolumn{3}{|l|}{ LAEF \% } \\
\hline \multicolumn{3}{|l|}{$\mathrm{ACO}(\mathrm{ml} / \mathrm{kg} / \mathrm{min})$} \\
\hline \multicolumn{3}{|c|}{ Maxium volume (ml/kg) } \\
\hline \multicolumn{3}{|c|}{ Minimum volume (ml/kg) } \\
\hline \multicolumn{3}{|c|}{ Atrial pre-contraction volume $(\mathrm{ml} / \mathrm{kg})$} \\
\hline \multicolumn{3}{|l|}{ Reservoir (ml/kg) } \\
\hline \multicolumn{3}{|c|}{ Conduction (ml/kg) } \\
\hline \multicolumn{3}{|c|}{ Contraction (ml/kg) } \\
\hline \multicolumn{3}{|l|}{$\mathrm{Vd}(\mathrm{ml} / \mathrm{kg})$} \\
\hline \multicolumn{3}{|l|}{ Vs (ml/kg) } \\
\hline \multicolumn{3}{|l|}{ LAEF \% } \\
\hline \multicolumn{3}{|l|}{$\operatorname{ACO}(\mathrm{ml} / \mathrm{kg} / \mathrm{min})$} \\
\hline \multicolumn{3}{|l|}{ St reservoir \% } \\
\hline \multicolumn{3}{|l|}{ St contraction \% } \\
\hline \multicolumn{3}{|l|}{ St conduction \% } \\
\hline \multicolumn{3}{|l|}{ CSI } \\
\hline \multicolumn{3}{|l|}{ StR reservoir \% } \\
\hline \multicolumn{3}{|l|}{ StR contraction $\%$} \\
\hline \multicolumn{3}{|l|}{ StR conduction $\%$} \\
\hline \multicolumn{3}{|c|}{$\begin{array}{l}\text { DMVD - degenerative mitral valve disease, } \mathrm{Vd}=\text { diastolic volume, } \mathrm{Vs}=\mathrm{sy} \\
\text { fraction, } \mathrm{ACO}=\text { atrial cardiac output, } \mathrm{St}=\mathrm{strain}, \mathrm{CSI}=\text { contraction strain }\end{array}$} \\
\hline \multicolumn{3}{|c|}{$\begin{array}{l}\text { Table 5. The intraclass correlation coefficient (ICC) } \\
\text { variability of left atrial echocardiographic volumes and } \\
\text { function measured by 2D-FTI and Simpson monoplanar } \\
\text { methods }\end{array}$} \\
\hline Variable & ICC & CI (95\%) \\
\hline LAEF (\%) & 0.2851 & -0.1027 a 0.5383 \\
\hline $\mathrm{ACI}(\mathrm{ml} / \mathrm{kg} / \mathrm{min})$ & 0.8680 & 0.7947 a 0.9153 \\
\hline LAdI (ml/kg) & 0.8759 & 0.8065 a 0.9204 \\
\hline LAsI (ml/kg) & 0.7967 & 0.6835 a 0.8694 \\
\hline
\end{tabular}

2D-FTI = Two-dimensional feature-tracking imaging, ICC $=$ intraclass correlation coefficient, $\mathrm{CI}=$ confidence interval, $\mathrm{LAEF}=$ left atrium ejection fraction, $\mathrm{ACI}=$ atrial cardiac index, $\mathrm{LAdI}=$ left atrial diastolic volume index, LAsI = left atrial systolic volume index.

The ICC was excellent for most of the LA volume variables that were measured using the two echocardiographic methods and was low for the LAEF (Table 5).

\section{DISCUSSION}

In the present study, 2D-FTI echocardiography and the single-plane Simpson's method proved useful for assessing the function of the LA by calculating the LAESV, LAEDV, CI, $\mathrm{LAV}_{\text {max }} \mathrm{LAV}_{\text {min' }}, \mathrm{LAV}_{\text {pre-a }}, \mathrm{LAS}$ reservoir, LAS contraction, and

cardiac conduction abnormalities in dogs with DMVD. The 2D-FTI analysis detected differences in the LAS of the healthy and class B2 dogs, which was indicative of early changes in the myocardial deformation of these animals. The images that were obtained were of sufficient quality to evaluate the dogs with structurally normal LA and dogs with LA remodelling. The animals were randomly selected according to the cardiology routine of our institute. For this reason, the number of females was higher in all of the groups that were studied, although previous studies showed that males are more commonly affected (Atkins et al. 2009, Fox 2012). However, the animal weight and age data indicated a mean value lower than $15 \mathrm{~kg}$ and an age higher than 6 years because DMVD occurs more frequently in smaller breeds of dogs and those older than 6 years (Atkins et al. 2009, Boswood et al. 2016).

There were significant differences in some of the variables that were obtained from conventional echocardiography as reported by Nakamura et al. (2017). The E wave and the E/ IVRT ratio, which are used to determine diastolic function and venous congestion, respectively, were significantly higher in Group B2 than in Group B1. An increased E wave indicates diastolic dysfunction with a pseudonormal filling pattern that is caused by an increased LA filling pressure and decreased ventricular compliance, which occurs with the progression of DMVD (Boon 2011).

The E/IVRT ratio in the B2 Group, although higher, is still below the predictive value indicating the development of 
CHF (E/IVRT > 2.5), but this increase is expected in the more advanced stages of the disease, since this index can be used to detect high ventricular filling pressure and CHF in dogs with DMVD (Schober et al. 2010). The LVDd N, LVDs N, and LA/Ao were used to classify the sample according to disease progression. These variables were higher in the B2 Group because the cardiac output is decreased and the hydrostatic pressure inside the cardiac chambers is increased in dogs with the more severe stages of DMVD, which activates neurohormonal systems (Oyama 2009). The long-term activation of these systems induces cardiac remodelling, which is characterised by eccentric myocardial hypertrophy (Bonagura \& Schober 2009).

The variables that were used to assess the LA function by feature tracking (SLA reservoir, SLA contraction, SLA conduit, CI, SLAR reservoir, SLAR contraction, and SLAR conduit) were also used to characterise the physiological changes during the cardiac cycle (Caivano et al. 2016). In the clinical routine, the LA size is determined by LA/Ao. LA function can also be evaluated by measuring the diastolic and systolic volume by conventional two-dimensional echocardiography. However, the LA structure is complex (including the conical left atrium, pulmonary veins, variable geometry, and small wall thickness), thus limiting the measurement of linear dimensions (Toaldo et al. 2018). Volume-based methods can provide more accurate estimates of the LA than can linear one-dimensional or area measurements, but they have limitations regarding their ability to estimate the size, function, and pathology of heart chambers (Höllmer et al. 2013, 2016, Hoit 2014). This fact is demonstrated by the observation that dogs with and without CHF may have similar degrees of atrial remodelling, as confirmed by their LA/Ao values (Caivano et al. 2016). Therefore, an analysis of atrial deformation by 2D-FTI may provide additional and useful information about the phasic function of the LA and the clinical cardiac status in asymptomatic dogs with DMVD, as demonstrated in this study.

To date, no veterinary studies have evaluated the use of the feature-tracking tool to assess atrial volume. In the present study, the LAEDV and CI that were obtained by 2D-FTI were significantly increased in the B2 Group as a function of the severity of MR, which worsens as the disease progresses, thus corroborating previous findings (Osuga et al. 2016, Höllmer et al. 2017). This result was confirmed by the association between these variables and LA/Ao (Fig.3).

Although there was no significant correlation between LA/Ao and SLA during contraction, there was a significant difference in these variables in the B2 Group when compared to the Control Group, demonstrating a reduction in contractile function in these patients. This finding reinforces the idea that linear measurements do not accurately evaluate the entire extent of the LA because its remodelling is asymmetrical (Tidholm et al. 2011). Nakamura et al. (2017) found a significant relationship between the LA/Ao and SLA during contraction because the mean LA/Ao value (1.92) in the B2 Group was higher than the mean value found in the present study (1.75). In cases of major LA remodelling and severe MR, fractional shortening decreases as the atrial diameter and pressure increase, which compromises LA contractile function - Frank-Starling mechanism (Payne et al. 1971), and these changes are reflected in this correlation. However, LA contractile function is even reduced in the early stages of remodelling, as demonstrated in the present study.

It is important to emphasise that the atrial systolic function depends on multiple factors, including ventricular compliance and LV end-diastolic pressure. Ventricular diastolic dysfunction can be evaluated by conventional echocardiography using the $\mathrm{E}$ wave and E/IVRT, which were higher in Group B2 in this study. In DMVD, as ventricular filling pressure progressively increases with a worsening of diastolic dysfunction, the LA acts predominantly as a conduit, enhancing the reduction in contractile function (Prioli et al. 1998, Rosca et al. 2011).

In addition, atrial remodelling involves singular adaptive events, which include changes in the composition of the extracellular matrix that include excessive proliferation of fibroblasts, myocyte hypertrophy, necrosis, and apoptosis (Lee et al. 2015, Janus et al. 2016). These structural changes significantly affect the properties of the LA myocardial wall, including relaxation and contractility and lead to a reduction in LA phasic functions, as demonstrated by Cameli et al. (2012) using two-dimensional speckle tracking echocardiography (2D-STE) in humans and Toaldo et al. (2018) using 2D-STE in dogs with DMVD. Similar to the above studies, the present study showed that the reduction in atrial function could be observed early using 2D-FTI in asymptomatic dogs with DMVD.

The CSI represents the percent contribution of the active contraction of the LA to the filling phase of the LV (Cameli et al. 2012). There was a negative correlation between this variable and LA/Ao, as previously reported by Baron et al. (2017). In contrast to the previous studies, this study found a significant difference in the CSI between all study groups. An explanation for this result could be that the early effect of MR on LA morphology and function can be detected only by 2D-FTI. In humans with MR, the variables that are obtained by 2D-STE echocardiography have been strongly correlated with atrial fibrosis (Cameli et al. 2011). However, there is no information in the veterinary literature on the role of fibrosis in the LA of dogs at the initial stage of DMVD. Another contributing factor is the age of the animals in the Control Group, and an age-related effect cannot be excluded because this group was younger than the other groups.

With respect to the single-plane Simpson's method, the LA volumes increased as the disease severity increased, as observed by Höllmer et al. (2017), and they were significantly higher in the asymptomatic dogs of class B2. Furthermore, Toaldo et al. (2018) demonstrated that the use of a volumetric method has a prognostic value in assessing LA size in dogs with DMVD compared with standard linear measurement. Previous studies have evaluated several methods of measuring atrial volume in the two-dimensional mode in healthy dogs (Dickson et al. 2017) and in dogs with DMVD (Höllmer et al. 2016, 2017, Toaldo et al. 2018). The large LA volume in dogs with DMVD is mainly a reflection of volume overload due to mitral regurgitant flow. LA enlargement is an important compensatory mechanism to prevent pulmonary congestion and maintain adequate ventricular filling volume. Another important factor was LA contraction, which decreased with increasing disease severity (Group 1 0.21 \pm 0.06 ; Group 2 $0.25 \pm 0.06$; Group 3 0.32 $\pm 0.08 ; \mathrm{p}<0.0001$ ) whereas LA volume and LA systolic volume were increased. The impaired LA contraction that occurs as DMVD progresses may be due to an increased afterload (end-diastolic LV filling pressure) and 
the exhaustion of the Frank-Starling mechanism by severe volume overload (Höllmer et al. 2017).

Caivano et al. (2016) measured the variability and repeatability of 2D-FTI measurements and found that the inter-observer variability was high for some variables (CS, SLA during contraction, and SLAR during contraction). Since the software automatically generates the curves after feature tracking during the cardiac cycle, the high variability of some variables may depend on the software that was used. In addition, the need for high-quality images for analysing the $2 \mathrm{D}-\mathrm{FTI}$ variables may increase the variability, whereas the measurements that require less computational power and lower quality images allow for higher repeatability, which was also observed by Baron et al. (2017).

The present study has some limitations; first this was a non-invasive study and was performed in companion animals. Therefore, invasive evaluations of the mechanical properties of the LA or afterload were not performed to confirm the reduced atrial function of the study animals. An alternative approach is magnetic resonance imaging, which is the gold standard in medicine to assess myocardial function and to validate the similarity between the methods. However, this analysis was not performed because of its high cost. Second, dogs that were affected with DMVD were older than those in the Control Group. However, it is difficult to obtain a group of older dogs without any degree of MR, given the pathophysiology of the disease.

Third, the results that we obtained may not be applicable to all clinical situations because of potential differences in echocardiography devices, software, equipment, examiner experience, and image quality, and these factors may affect measurements and data variability, as demonstrated in other studies (Caivano et al. 2016, Baron et al. 2017, Nakamura et al. 2017).

Notwithstanding, the study demonstrated that 2D-FTI echocardiography and the single-plane Simpson's method could be used to determine LA function in dogs with DMVD. The results we obtained provide new perspectives on LA deformation and other variables, allowing for a more comprehensive quantification and a better understanding of the role of the LA in the pathophysiology of DMVD.

\section{CONCLUSIONS}

The present study demonstrated that DMVD causes changes in atrial function, especially in the contraction phase, and that 2D-FTI echocardiography was a sensitive method that could be used for the early detection of LA dysfunction. The use of this tool allows for the measurement of atrial deformation even in asymptomatic animals, and the progressive decline in atrial function can be measured as the disease progresses.

Therefore, future studies can use 2D-FTI as a prognostic indicator in dogs with DMVD. The single-plane Simpson's method could differentiate between asymptomatic animals either with or without atrial remodelling, and its effectiveness was similar to that of 2D-FTI echocardiography.

\footnotetext{
Acknowledgements.- The authors are grateful to the "Coordenação de Aperfeiçoamento de Pessoal de Nível Superior" (CAPES) for the scholarship provided to Mariana de Resende Coelho.
}

Conflict of interest statement.- The authors have no competing interests.

\section{REFERENCES}

Atkins C., Bonagura J., Ettinger S., Fox P., Gordon S., Haggstrom J., Hamlin R., Keene B., Luis-Fuentes V. \& Stepien R. 2009. Guidelines for the diagnosis and treatment of canine chronic valvular heart disease. J. Vet. Intern. Med. 23(6):1142-1150. <http://dx.doi.org/10.1111/j.1939-1676.2009.0392.x>

Baron T.M., Romito G., Guglielmini C., Diana A., Pelle N.G., Contiero B. \& Cipone M. 2017. Assessment of left atrial deformation and function by 2-dimensional speckle tracking echocardiography in healthy dogs and dogs with myxomatous mitral valve disease. J. Vet. Intern. Med. 31(3):641-649. <http://dx.doi.org/10.1111/jvim.14722> <PMid:28455877>

Blume G.G., Mcleod C.J., Barnes M.E., Seward J.B., Pellikka P.A., Bastiansen P.M. \& Tsang T.S. 2011. Left atrial function: Physiology, assessment, and clinical implications. Eur. J. Echocardiography 12(6):421-430. <http:// dx.doi.org/10.1093/ejechocard/jeq175> <PMid: 21565866>

Bonagura J.D. \& Schober K.E. 2009. Can ventricular function be assessed by echocardiography in chronic canine mitral valve disease? J. Small Anim. Pract. 50(suppl.1):12-24. <http://dx.doi.org/10.1111/j.1748-5827.2009.00803.x> <PMid:19765216>

Boon J.A. 2011. Evaluation of size, function, and hemodynamics, p.206-334. In: Boon J.A. (Ed.), Veterinary Echocardiography. 2nd ed. J. Willey, New Jersey.

Borgarelli M. \& Buchanan J.W. 2012. Historical review, epidemiology and natural history of degenerative mitral valve disease. J. Vet. Cardiol. 14(1):93101. <http://dx.doi.org/10.1016/j.jvc.2012.01.011> <PMid:22386588>

Boswood A., Häggström J., Gordon S.G., Wess G., Stepien R.L., Oyama M.A., Keene B.W., Bonagura J., MacDonald K.A., Patteson M., Smith S., Fox P.R., Sanderson K., Woolley R., Szatmári V., Menaut P., Church W.M., O'Sullivan M.L., Jaudon J.P., Kresken J.G., Rush J., Barrett K.A., Rosenthal S.L., Saunders A.B., Ljungvall I., Deinert M., Bomassi E., Estrada A.H., Fernandez Del Palacio M.J., Moise N.S., Abbott J.A., Fujii Y., Spier A., Luethy M.W., Santilli R.A., Uechi M., Tidholm A. \& Watson P. 2016. Effect of pimobendan in dogs with preclinical myxomatous mitral valve disease and cardiomegaly: the EPIC study, a randomized clinical trial. J. Vet. Intern. Med. 30(6):1765-1779. <http://dx.doi.org/10.1111/jvim.14586><PMid:27678080>

Caivano D., Rishniw M., Patata V., Giorgi M.E., Birettoni F. \& Porciello F. 2016. Left atrial deformation and phasic function determined by 2-dimensional speckle tracking echocardiography in healthy dogs. J. Vet. Cardiol. 18(2):146155. <http://dx.doi.org/10.1016/j.jvc.2016.01.004><PMid:26993761>

Cameli M., Lisi M., Giacomin E., Caputo M., Navarri R., Malandrino A., Ballo P., Agricola E. \& Mondillo S. 2011. Chronic mitral regurgitation: left atrial deformation analysis by two dimensional speckle tracking echocardiography. Echocardiography 28(3):327-334. <http://dx.doi. org/10.1111/j.1540-8175.2010.01329.x><PMid:21323986>

Cameli M., Lisi M., Righini F.M., Focardi M., Alfieri O. \& Mondillo S. 2012. Left atrial speckle tracking analysis in patients with mitral insufficiency and history of paroxysmal atrial fibrillation. Int. J. Cardiovasc. Imag. 28(7):16631670. <http://dx.doi.org/10.1007/s10554-011-9987-y><PMid:22130899>

Cornell C.C., Kittleson M.D., Della Torre P., Häggström J., Lombard C.W., Pedersen H.D., Vollmar A. \& Wey A. 2004. Allometric Scaling of M-Mode Cardiac Measurements in Normal Adult Dogs. J. Vet. Intern. Med. 18(3):311321. <http://dx.doi.org/10.1892/0891-6640(2004)18<311:asomcm >2. 0. co;2><PMid:15188817>

Decloedt A., Verheyen T., Sys S., De Clercq D. \& Van Loon G. 2011. Quantification of left ventricular longitudinal strain, strain rate, velocity, and displacement in healthy horses by 2-dimensional speckle tracking. J. Vet. Intern. Med. 25(2):330-338. <http://dx.doi.org/10.1111/j.1939-1676.2010.0663.x> $<$ PMid:21382074>

Dickson D., Caivano D., Matos J.N., Summerfield N. \& Rishniw M. 2017. Two-dimensional echocardiographic estimates of left atrial function in healthy dogs and dogs with myxomatous mitral valve disease. J. Vet. Cardiol. 19(6):469-479. <http://dx.doi.org/10.1016/j.jvc.2017.09.003> $<$ PMid:29111284> 
Fleiss J. 1981. Statistical Methods for Rates and Proportions. 2nd ed. John Wiley, New York. 352p

Fox P.R. 2012. Pathology of myxomatous mitral valve disease in the dog. J. Vet. Cardiol. 14(1):103-126. <http://dx.doi.org/10.1016/j.jvc.2012.02.001> <PMid:22386587>

Hoit B.D. 2014. Left atrial size and function. J. Am. Coll. Cardiol. 63(6):493505. <http://dx.doi.org/10.1016/j.jacc.2013.10.055><PMid:24291276>

Höllmer M. Willesen J.L., Tolver A. \& Koch J. 2013. Left atrial volume and phasic function in clinically healthy dogs of 12 different breeds. Vet. J. 197(3):639645. <http://dx.doi.org/10.1016/j.tvjl.2013.05.045><PMid:23838204>

Höllmer M., Willesen J.L., Tolver A. \& Koch J. 2016. Comparison of four echocardiographic methods to determine left atrial size in dogs. J. Vet. Cardiol. 18(2):137-145. <http://dx.doi.org/10.1016/j.jvc.2016.02.001> $<$ PMid:27009978>

Höllmer M., Willesen J.L., Tolver A. \& Koch J. 2017. Left atrial volume and function in dogs with naturally occurring myxomatous mitral valve disease. J. Vet. Cardiol. 19(1):24-34. <http://dx.doi.org/10.1016/j.jvc.2016.08.006> $<$ PMid:27825670>

Janus I., Noszczyk-Nowak A., Nowak M., Ciaputa R., Kandefer-Gola M. \& Pasławska U. 2016. A comparison of the histopathologic pattern of the left atrium in canine dilated cardiomyopathy and chronic mitral valve disease. BMC Vet. Res. 12:1-7. <http://dx.doi.org/10.1186/s12917-015-0626-z> $<$ PMid:26728624>

Lee J., Mizuno M., Mizuno T., Harada K. \& Uechi M. 2015. Pathologic manifestations on surgical biopsy and their correlation with clinical índices in dogs with degenerative mitral valve disease. J. Vet. Intern. Med. 29(5):1313-1321. <http://dx.doi.org/10.1111/jvim.13587><PMid:26214756>

Matsumoto A.Y., Mancuso F.J., Tatani S.B., Machado C.V., Hotta V.T. \& Moisés V.A. 2014. Avaliação ecocardiográfica da função atrial esquerda: aspectos fisiológicos e clínicos. Revta DIC 27(2):87-96. <http://dx.doi. org/10.5935/2318-8219.20140015>

Nakamura K., Kawamoto S., Osuga T., Morita T., Sasaki N., Morishita K., Ohta H. \& Takiguchi M. 2017. Left atrial strain at different stages of myxomatous mitral valve disease in dogs. J. Vet. Intern. Med. 31(2):316-325. <http:// dx.doi.org/10.1111/jvim.14660><PMid:28145607>

Osuga T., Nakamura K., Morita T., Nisa K., Yokoyama N., Sasaki N., Morishita K., Ohta H. \& Takiguchi M. 2016. Effects of experimental cardiac volume loading on left atrial phasic function in healthy dogs. Am. J. Vet. Res. 77(9):952-960. <http://dx.doi.org/10.2460/ajvr.77.9.952><PMid:27580106>
Oyama M.A. 2009. Neurohormonal activation in canine degenerative mitral valve disease: implications on pathophysiology and treatment. J. Small Anim. Pract. 50(suppl.1):3-11. <http://dx.doi.org/10.1111/j.1748-5827.2009.00801.x> <PMid:19765215>

Payne R.M., Stone H.L. \& Engelken E.J. 1971. Atrial function during volume loading. J. Appl. Physiol. 31(3):326-331. <http://dx.doi.org/10.1152/ jappl.1971.31.3.326><PMid:5111850>

Prioli A., Marino P., Lanzoni L. \& Zardini P. 1998. Increasing degrees of left ventricular filling impairment modulate left atrial function in humans. Am. J. Cardiol. 82(6):756-761. <http://dx.doi.org/10.1016/s00029149(98)00452-4><PMid:9761086>

Rosca M., Lancellotti P., Popescu B.A. \& Piérard L.A. 2011. Left atrial function: pathophysiology, echocardiographic assessment, and clinical applications. Heart 97(23):1982-1989. <http://dx.doi.org/10.1136/ heartjnl-2011-300069> <PMid:22058287>

Schober K.E., Hart T.M., Stern J.A., Li X., Samii V.F., Zekas L.J., Scansen B.A. \& Bonagura J.D. 2010. Detection of congestive heart failure in dogs by Doppler echocardiography. J. Vet. Intern. Med. 24(6):1358-1368. <http://dx.doi. org/10.1111/j.1939-1676.2010.0592.x> <PMid:20840304>

Thomas W.P., Gaber C.E, Jacobs G.J., Kaplan P.M., Lombard C.W., Moise N.S. \& Moses B.L. 1993. Recommendations for standards in transthoracic two dimensional echocardiography in the dog and cat. J. Vet. Intern. Med. 7(4):247-252. <http://dx.doi.org/10.1111/j.1939-1676.1993.tb01015.x> $<$ PMid:8246215>

Tidholm A., Bodegård-westling A., Höglund K., Ljungvall I. \& Häggström J. 2011. Comparisons of 2- and 3-dimensional echocardiographic methods for estimation of left atrial size in dogs with and without myxomatous mitral valve disease. J. Vet. Intern. Med. 25(6):1320-1327.<http://dx.doi. org/10.1111/j.1939-1676.2011.00812.x><PMid: 22092623>

Toaldo M.B., Romito G., Guglielmini C., Diana A., Pelle N.G., Contiero B. \& Cipone M. 2017. Assessment of left atrial deformation and function by 2-dimensional speckle tracking echocardiography in healthy dogs and dogs with myxomatous mitral valve disease. J. Vet. Intern. Med. 31(3):641-649. <http://dx.doi.org/10.1111/jvim.14722><PMid: 28455877>

Toaldo M.B., Romito G., Guglielmini C., Diana A., Pelle N.G., Contiero B. \& Cipone M. 2018. Prognostic value of echocardiographic indices of left atrial morphology and function in dogswith myxomatousmitral valve disease. J. Vet. Intern. Med. 32(3):914-921. <http://dx.doi.org/10.1111/ jvim.15093> <PMid: 29572938> 